\title{
Case Report \\ Development of Cutaneous Leishmaniasis after Leishmania Skin Test
}

\author{
Paulo R. Machado, ${ }^{1,2}$ Augusto M. Carvalho, ${ }^{3}$ Gustavo U. Machado, ${ }^{3}$ \\ Marina L. Dantas, ${ }^{4}$ and Sérgio Arruda ${ }^{4}$ \\ ${ }^{1}$ Serviço de Imunologia, Hospital Universitário Prof. Edgard Santos, Universidade Federal da Bahia, Salvador, BA 40000, Brazil \\ ${ }^{2}$ Instituto Nacional de Ciência e Tecnologia de Doenças Tropicais, CNPq/MCT, Salvador, BA 40000, Brazil \\ ${ }^{3}$ Cursos de Medicina e Biomedicina, Escola Bahiana de Medicina e Saúde Pública, Salvador, BA 40000, Brazil \\ ${ }^{4}$ Centro de Pesquisas Gonçalo Moniz, LASP, Fundação Oswaldo Cruz, Salvador, BA 40000, Brazil
}

Correspondence should be addressed to Paulo R. Machado, prlmachado@uol.com.br

Received 26 May 2011; Revised 1 September 2011; Accepted 1 September 2011

Academic Editor: Abhay R. Satoskar

Copyright ( $) 2011$ Paulo R. Machado et al. This is an open access article distributed under the Creative Commons Attribution License, which permits unrestricted use, distribution, and reproduction in any medium, provided the original work is properly cited.

\begin{abstract}
Thirty-year-old female with a previous history of a cutaneous ulcer suspicious of leishmaniasis 20 years ago presented with a new complaint of a depressed papular lesion $8 \times 7 \mathrm{~mm}$ in the right lower extremity. The lesion was of 10-day duration. Because early cutaneous leishmaniasis (CL) lesions may have a non-ulcerated appearance, a Leishmania skin test (LST) was performed on the forearm with a strong positive result $(38 \times 32 \mathrm{~mm})$. After 8 days, the lesion in the leg, which was diagnosed as folliculitis, completely healed. However, a typical CL ulcer $(26 \times 24 \mathrm{~mm})$ developed at the LST site. Histopathology of the new lesion did not identifiy parasites, but the findings were consistent with a diagnosis of CL. Further analysis identified amastigotes by immunohistochemical stain. Mononuclear cells harvested from the patient were stimulated with Leishmania antigen and showed high levels of production of both tumor necrosis factor-alpha (TNF- $\alpha$ ) and interferon-gamma (IFN- $\gamma$ ): $2,943 \mathrm{pg} / \mathrm{mL}$ and 2,313 pg/mL, respectively. After 40 days of treatment with antimony and pentoxifylline, the ulcer resolved. The development of CL at the LST site suggests a strong Th1 immune response, and it is an in vivo documentation of the role of the host immune response in the pathology of CL. It teaches us that LST should be cautiously, if at all, used in patients with self-healing CL ulcers.
\end{abstract}

\section{Introduction}

Cutaneous leishmaniasis (CL) due to Leishmania braziliensis is characterized by a well-delimited ulcer with raised borders and localized mainly on the inferior limbs $[1,2]$. In $\mathrm{CL}$, parasites are not easily found in the lesion. The sensitivity of serological tests is low. However, the predictive value of the delayed-type hypersensitivity Leishmania skin test (LST) is high [3,4]. Thus, when parasites are not detected, a positive LST accompanied by typical ulcer and histopathological findings compatible with leishmaniasis is accepted as diagnostic standard for CL in endemic areas [3]. The test is considered safe, and its side effects are mild [4]. Rarely topical steroids are needed to attenuate pain, erythema, or eruptive lesions that appear after the test is administered. Both parasite and host immunological factors participate in the pathogenesis of CL. Although the ability to mount a type 1 immune response to Leishmania is associated with protection [5], in L. braziliensis infection, the tissue damage is associated with an exaggerated cell-mediated immune response [6,7]. This case represents in vivo evidence of the host immune response in the pathogenesis of CL ulcers.

\section{Case Presentation}

RJS, a 30-year-old woman, was seen at the health post of Corte de Pedra, Tancredo Neves-Bahia, a reference center for diagnosis and treatment of CL. The patient complained of a small papular lesion in her right leg developing over seven to 10 days. When she was 10 years of age, she had an ulcer in the left thigh suspicious of CL that spontaneously healed in about 4 months. Given her prior history of ulcer, she decided to seek help at the health post when the new lesion appeared. 


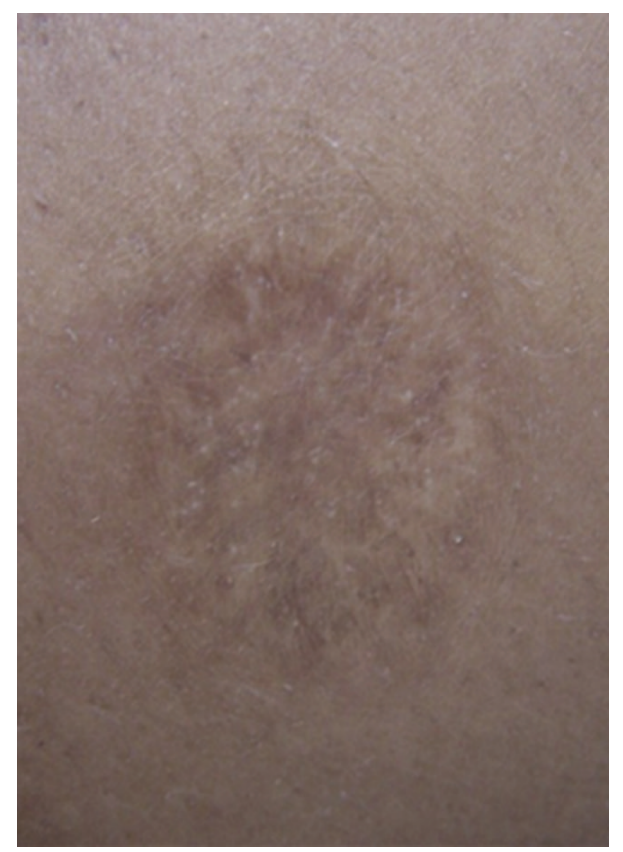

FIGURE 1: A well-delimited atrophic scar in the left thigh measuring $30 \times 20 \mathrm{~mm}$.

On physical examination, a depressed papular lesion measuring $8 \times 7 \mathrm{~mm}$ in the right leg suspicious of folliculitis was noted. There was also a well-defined atrophic scar in the left thigh, measuring $30 \times 20 \mathrm{~mm}$ (Figure 1). There was no lymphadenopathy. Because early CL lesions in L. braziliensis infection may have a papular and nonulcerated aspect [8] and the patient lived in an endemic area, the diagnosis of CL was suspected. LST was prepared as previously described [9]. Briefly promastigotes of L. amazonensis were disrupted initially by multiple freeze and thaw and later by sonication. The material was adjusted to $250 \mu \mathrm{g} / \mathrm{mL}$ with sterile PBS containing Tween 80 and phenol [9]. An intradermal injection of $0.1 \mathrm{~mL}$ was administered in her left forearm. After 48 hours, the intradermal reaction was highly positive with an induration of $38 \times 32 \mathrm{~mm}$. Eight days after the skin test, while the folliculitis in the right leg disappeared, a cutaneous round ulcer with raised borders measuring $26 \times 24 \mathrm{~mm}$, typical of leishmaniasis, was observed in the site where the LST was administered (Figure 2). The clinical picture was typical of an ulcerated CL lesion, but the culture of the aspirated material from this lesion was negative for Leishmania. The histopathological analysis (Figure 3) showed chronic perivascular inflammation with granuloma formation and the presence of neutrophils, lymphocyte, monocyte, and plasma cells. Parasites were not identified, but a few amastigote forms were detected by immunohistochemical analysis performed with rabbit antiLeishmania braziliensis antibody in skin sections.

Determination of cytokine production was performed by ELISA (R\&D Systems, Minneapolis, Minn, USA) in supernatants of peripheral blood mononuclear cells stimulated with soluble Leishmania antigen (SLA) for 72 hours [6]. TNF- $\alpha$ and IFN- $\gamma$ levels were $47 \mathrm{pg} / \mathrm{mL}$ and $0 \mathrm{pg} / \mathrm{mL}$,

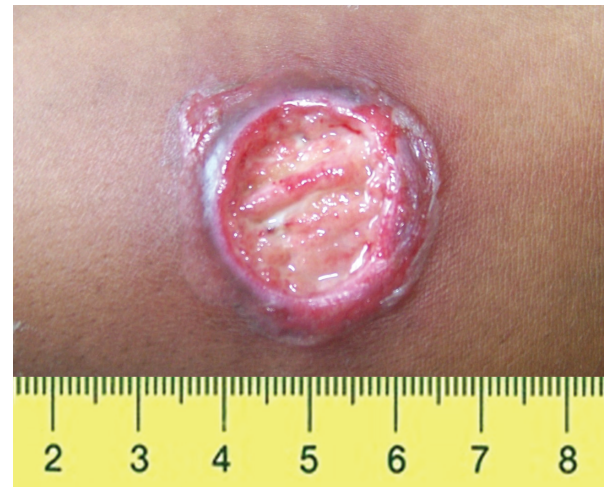

FIGURE 2: Cutaneous round ulcer with raised borders measuring $26 \times 24 \mathrm{~mm}$ in the forearm where the Montenegro skin test was performed.

respectively, in unstimulated cultures and were $2,943 \mathrm{pg} / \mathrm{mL}$ and $2,313 \mathrm{pg} / \mathrm{mL}$, respectively, in SLA-stimulated cultures. These values were similar to those detected in 3 patients with CL who were evaluated on the same day: TNF- $\alpha$ : $2,139 \pm 953.8$; IFN $-\gamma: 3,653 \pm 312.6$. The patient was treated with pentavalent antimony (Glucantime) in a dosage of $20 \mathrm{mg} / \mathrm{kg} /$ day and pentoxifylline $400 \mathrm{mg}$ tid for 20 days. Pentoxifylline has anti-inflammatory properties, and it has been previously shown that its use in combination with antimony is more effective than antimony alone in the treatment of tegumentary leishmaniasis $[10,11]$. The ulcerated lesion in the left forearm was completely healed 40 days after the initiation of therapy (Figure 4).

\section{Discussion}

This paper calls attention to a patient who had a past (20 years prior) self-healing ulcerated lesion compatible with CL and who developed a typical ulcer of CL in the place where a LST was performed. Although parasites were found in the immunohistochemical analysis, there are strong indications that the cutaneous ulcer observed in this patient was due predominantly to the skin test with Leishmania antigen: (1) despite that parasites DNA are found in the scar of patients cured of tegumentary leishmaniasis, reactivation is uncommon except in patients with HIV [12]; (2) the development of cutaneous ulcer caused by L. braziliensis usually takes 1-2 months and it is preceded by lymphadenopathy, papular or nodular lesion, and a superficial ulcer, features not observed in this patient $[8,13] ;(3)$ the lesion occurred in the same place where the skin test was performed; (4) while classical CL ulcers heal after 60 or 90 days of antimony therapy [13], the cutaneous ulcer presented here healed in less than 40 days. Together, these data suggest that $\mathrm{CL}$ developed in this patient was due to a skin test performed in the location.

Host and parasite factors participate in the pathogenesis of tegumentary leishmaniasis $[2,6,7]$. The persistence of the parasites in patients with self-healing CL is important to maintain the $\mathrm{T}$ cell response after clinical cure. 


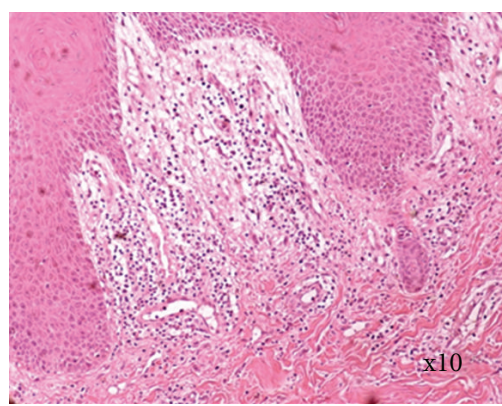

(a)

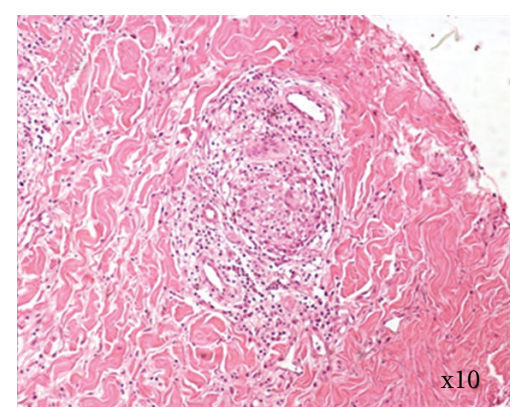

(b)

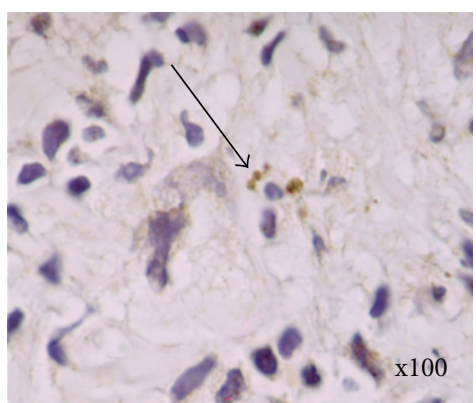

(c)

FIgURE 3: Hematoxylin-eosin staining of biopsy. (a) Edema and chronic inflammation in the papillary dermis (10x). (b) Granuloma in the dermis (10x). (c) Immunohistochemistry staining of L. braziliensis amastigotes ((100x) arrow).

It is interesting that, in this case, amastigotes were found in a place where the LST was performed. Prior studies have shown parasite DNA in scars of CL patients [14], but herein we found amastigotes in the tissue where the new ulcer developed. These parasite forms were not present in the LST because it was prepared with promastigotes, and as previously described it contains only SLA [9]. Moreover, there is strong evidence for the role of $\mathrm{T}$ cell responses in the pathogenesis of L. braziliensis infection including (1) a strong inflammatory reaction in tissue in the absence or with very few parasites in the lesion [15]; (2) a correlation between frequency of $\mathrm{CD}^{+} \mathrm{T}$ cells expressing IFN- $\gamma$ and TNF- $\alpha$ and size of the lesion [7]; (3) a correlation between $\mathrm{CD}^{+}{ }^{+} \mathrm{T}$ cell activation markers expression and size of the lesion [7]; (4) presence of cytotoxicity in preulcerative lesions [16]; (5) a correlation between granzyme expression by CD8 $\mathrm{T}$ cells and the inflammatory reaction in the tissue [17]; (6) development of ulcers despite antimony therapy in patients diagnosed with early and preulcerative CL $[8,13]$.

In the present case, the patient had a history of a previous ulcer that self-healed. Self-healing of CL usually occurs after 6 months of the initiation of the ulcer [18]. Immunological studies in patients with self-healing CL showed that there are a high lymphocyte proliferation and high production of IFN- $\gamma$ in cultures stimulated with SLA [18]. The presence of a strong type 1 immune response in subjects with selfhealing disease is probably due to the presence of the parasite and the persistent stimulation of the immune response. The immune response in the young lady presented in this paper was similar to that observed in patients with active CL, despite the fact that her leishmaniasis lesion had occurred 20 years previously. In such case, the development of a typical CL ulcer after the intradermal injection of Leishmania antigen could be explained by the activation of antigenreactive $\mathrm{T}$ cells that, after challenge, induced tissue damage at the site the antigen was inoculated. The patient was treated with antimony plus pentoxifylline, a TNF- $\alpha$ inhibitor in part because of the previous observation that combination therapy was more effective $[10,11]$ and also because we believe that the inflammatory response played an important role in the development of the ulcer at the site where LST was applied. It is known that TNF- $\alpha$ plays a key role in controlling parasite multiplication in the initial phase of

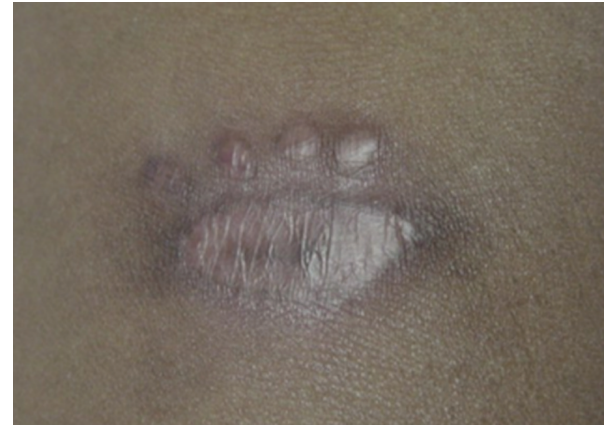

FIGURE 4: Scar in the forearm 40 days after the initiation of therapy.

Leishmania infection [19], but it is also associated with ulcer development $[6,7]$. Therefore, it is possible that modulation of the immune response by pentoxifylline improved the therapeutic response in this patient $[10,11]$.

This paper emphasizes the role of the immune response as a cause of the tissue damage in CL. Moreover it illustrates important clinical lessons: first, that antimony therapy should be provided even for patients who present with selfhealing CL secondary to L. braziliensis infection; second, that the LST should be used with caution, if at all, in patients with self-healing CL.

\section{Acknowledgments}

Elbe Silva and Cristiano Franco are acknowledged for secretarial assistance, Ednaldo Lima do Lago for patient care in the endemic area, and Cristina Toledo-Cornell for help with proofreading the paper.

\section{References}

[1] T. C. Jones, W. D. Johnson, A. C. Barretto, E. Lago, and P. D. Marsden, "Epidemiology of American cutaneous leishmaniasis due to Leishmania braziliensis," Journal of Infectious Diseases, vol. 156, no. 1, pp. 73-83, 1987.

[2] M. Barral-Netto, P. Machado, and A. Barral, "Human cutaneous leishmaniasis: recent advances in physiopathology and treatment," European Journal of Dermatology, vol. 5, no. 2, pp. 104-113, 1995. 
[3] C. C. Cuba, E. A. Llanos-Cuentas, A. C. Barreto et al., "Human mucocutaneous leishmaniasis in Três Braços, Bahia-Brazil, an area of Leishmania braziliensis braziliensis transmission. I. Laboratory diagnosis," Revista da Sociedade Brasileira de Medicina Tropical, vol. 17, pp. 161-167, 1984.

[4] K. A. Weigle, L. Valderrama, A. L. Arias, C. Santrich, and N. G. Saravia, "Leishmanin skin test standardization and evaluation of safety, dose, storage, longevity of reaction and sensitization," American Journal of Tropical Medicine and Hygiene, vol. 44, no. 3, pp. 260-271, 1991.

[5] J. P. Sypek, C. L. Chung, S. E. H. Mayor et al., "Resolution of cutaneous leishmaniasis: interleukin 12 initiates a protective T helper type 1 immune response," Journal of Experimental Medicine, vol. 177, no. 6, pp. 1797-1802, 1993.

[6] O. Bacellar, H. Lessa, A. Schriefer et al., "Up-regulation of Th1type responses in mucosal leishmaniasis patients," Infection and Immunity, vol. 70, no. 12, pp. 6734-6740, 2002.

[7] L. R. V. Antonelli, W. O. Dutra, R. P. Almeida, O. Bacellar, E. M. Carvalho, and K. J. Gollob, "Activated inflammatory T cells correlate with lesion size in human cutaneous leishmaniasis," Immunology Letters, vol. 101, no. 2, pp. 226-230, 2005.

[8] P. Machado, C. Araújo, A. T. Da Silva et al., "Failure of early treatment of cutaneous leishmaniasis in preventing the development of an ulcer," Clinical Infectious Diseases, vol. 34, no. 12, pp. E69-E73, 2002.

[9] S. G. Reed, R. Badaró, H. Masur et al., "Selection of a skin test antigen for American visceral leishmaniasis," American Journal of Tropical Medicine and Hygiene, vol. 35, no. 1, pp. 79-85, 1986.

[10] P. R. L. Machado, H. Lassa, M. Lessa et al., "Oral pentoxifylline combined with pentavalent antimony: a randomized trial for mucosal leishmaniasis," Clinical Infectious Diseases, vol. 44, no. 6, pp. 788-793, 2007.

[11] G. Sadeghian and M. A. Nilforoushzadeh, "Effect of combination therapy with systemic glucantime and pentoxifylline in the treatment of cutaneous leishmaniasis," International Journal of Dermatology, vol. 45, pp. 819-821, 2006.

[12] J. A. L. Lindoso, R. N. Barbosa, M. P. Posada-Vergara et al., "Unusual manifestations of tegumentary leishmaniasis in AIDS patients from the New World," British Journal of Dermatology, vol. 160, no. 2, pp. 311-318, 2009.

[13] A. Unger, S. O’Neal, P. R. L. Machado et al., "Association of treatment of American cutaneous leishmaniasis prior to ulcer development with high rate of failure in Northeastern Brazil," American Journal of Tropical Medicine and Hygiene, vol. 80, no. 4, pp. 574-579, 2009.

[14] M. G. Mendonça, A. E. F. De Brito, E. H. G. Rodrigues, V. Bandeira, M. L. Jardim, and F. G. C. Abath, "Persistence of Leishmania parasites in scars after clinical cure of american cutaneous leishmaniasis: is there a sterile cure?" Journal of Infectious Diseases, vol. 189, no. 6, pp. 1018-1023, 2004.

[15] A. L. Bittencourt and A. Barral, "Evaluation of the histopathological classifications of American cutaneous and mucocutaneous leishmaniasis," Memorias do Instituto Oswaldo Cruz, vol. 86, no. 1, pp. 51-56, 1991.

[16] P. Machado, J. Kanitakis, R. Almeida, A. Chalon, C. Araújo, and E. M. Carvalho, "Evidence of in situ cytotoxicity in American cutaneous leishmaniasis," European Journal of Dermatology, vol. 12, no. 5, pp. 449-451, 2002.

[17] D. R. Faria, P. E. A. Souza, F. V. Durães et al., "Recruitment of CD8(+) $\mathrm{T}$ cells expressing granzyme $\mathrm{A}$ is associated with lesion progression in human cutaneous leishmaniasis," Parasite Immunology, vol. 31, no. 8, pp. 432-439, 2009.
[18] E. M. Carvalho, D. C. Filho, O. Bacellar, R. P. Almeida, H. Lessa, and H. Rocha, "Characterization of the immune response in subjects with self-healing cutaneous Leishmaniasis," American Journal of Tropical Medicine and Hygiene, vol. 53, no. 3, pp. 273-277, 1995.

[19] F. Y. Liew, Y. Li, and S. Millott, "Tumour necrosis factor (TNF- $\alpha$ ) in leishmaniasis. II. TNF- $\alpha$-induced macrophage leishmanicidal activity is mediated by nitric oxide from Larginine," Immunology, vol. 71, no. 4, pp. 556-559, 1990. 


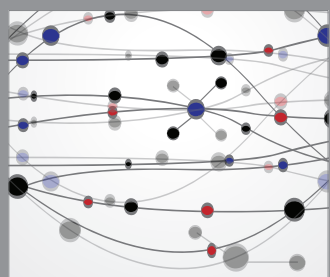

The Scientific World Journal
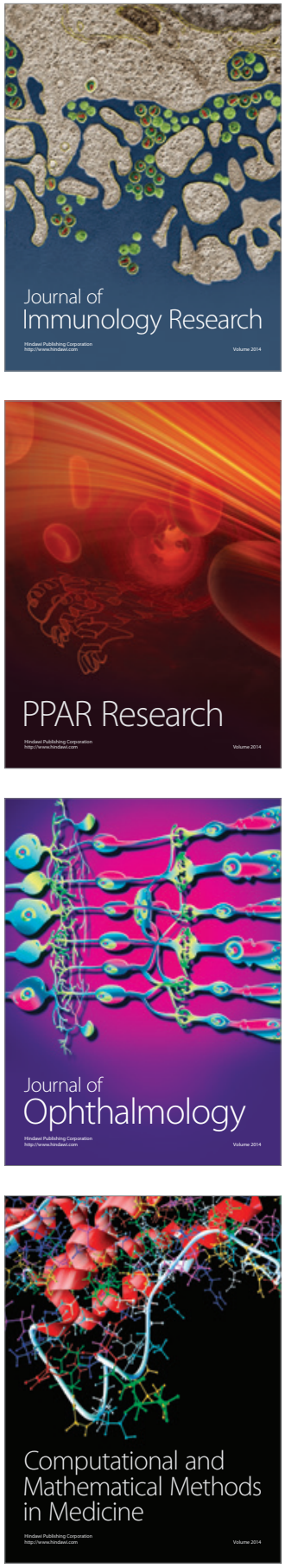

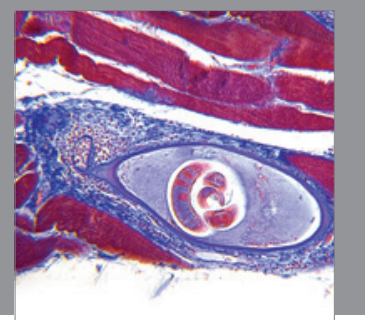

Gastroenterology

Research and Practice
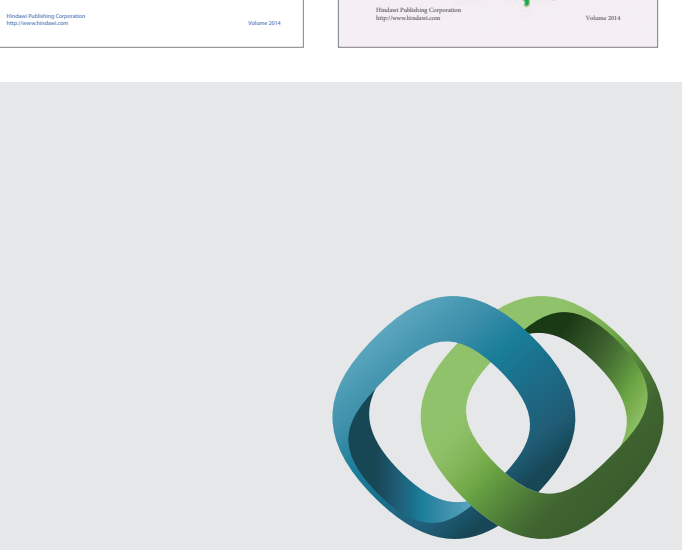

\section{Hindawi}

Submit your manuscripts at

http://www.hindawi.com
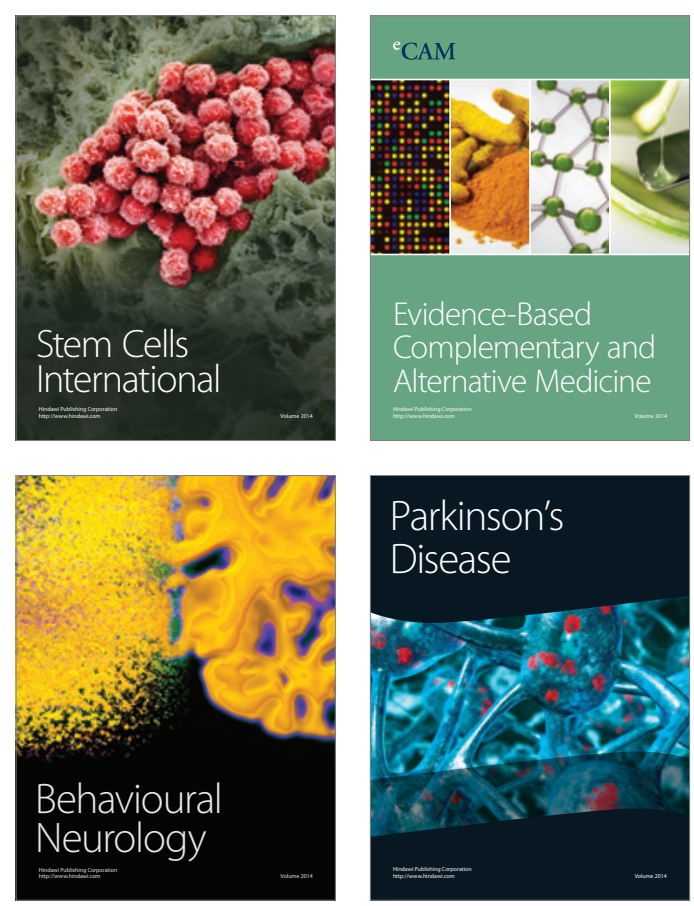

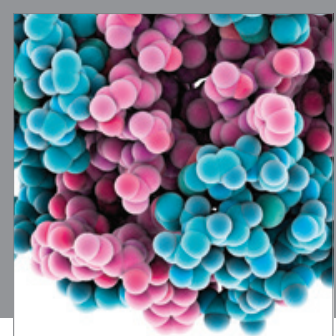

Journal of
Diabetes Research

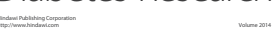

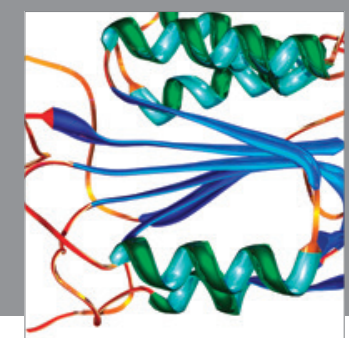

Disease Markers
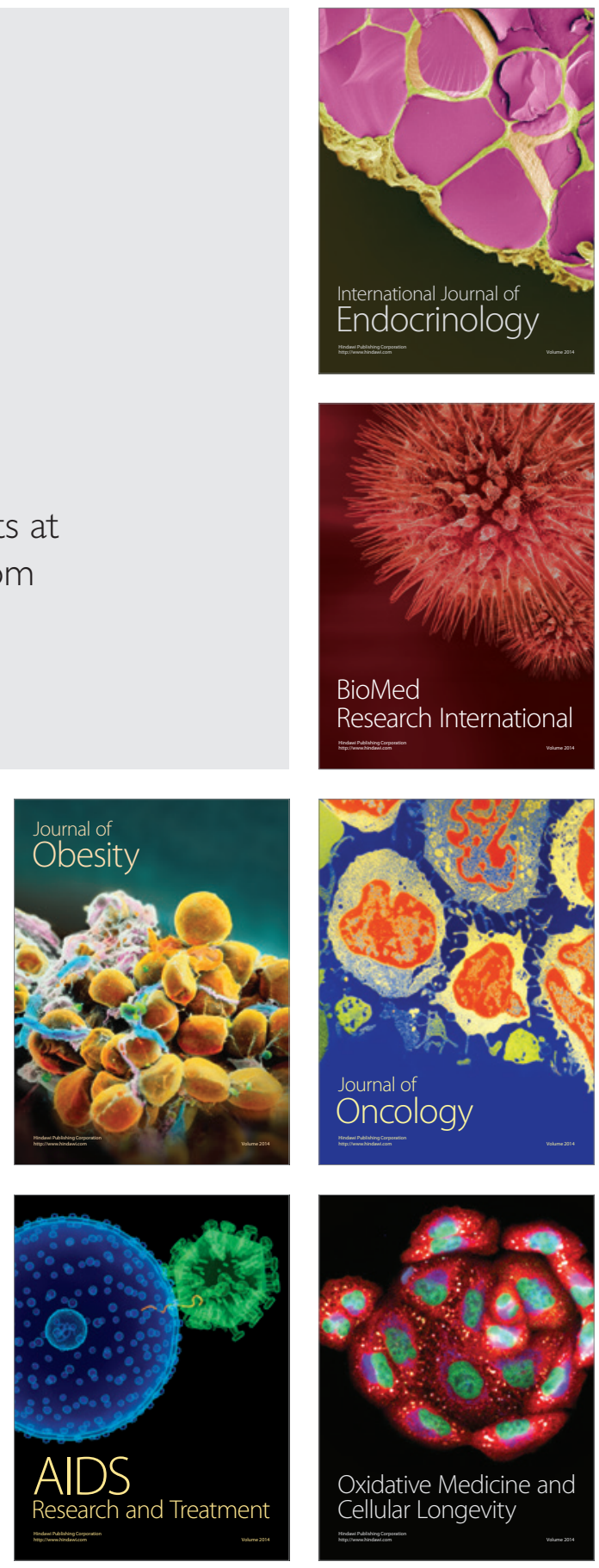